\section{Transgenic expression of dentin phosphoprotein inhibits skeletal development}

\author{
H. Zhang, ${ }^{1}$ P. Liu, ${ }^{2}$ S. Wang, ${ }^{1}$ C. Liu, ${ }^{1}$ \\ P. Jani, ${ }^{1}$ Y. Lu, ${ }^{1}$ C. Qin ${ }^{1}$ \\ 'Department of Biomedical Sciences and \\ Center for Craniofacial Research and \\ Diagnosis, Texas A\&M University Baylor \\ College of Dentistry, Dallas, TX, USA \\ 2Department of Periodontics, Harbin \\ Medical University School of \\ Stomatology, Harbin, Heilongjiang, China
}

\begin{abstract}
Dentin sialophosphoprotein (DSPP) is proteolytically processed into an $\mathrm{NH}_{2}$-terminal fragment called dentin sialoprotein (DSP) and a $\mathrm{COOH}$-terminal fragment known as dentin phosphoprotein (DPP). These two fragments are believed to perform distinct roles in formation of bone and dentin. To investigate the functions of DPP in skeletal development, we generated transgenic mice to overexpress hemagglutinin (HA)-tagged DPP under the control of a $3.6 \mathrm{~kb}$ type I collagen (Collal) promoter (designated as Colla1-HA-DPP). The Collal-HA-DPP transgenic mice were significantly smaller by weight, had smaller skeletons and shorter long bones than their wild type littermates, as demonstrated by X-ray radiography. They displayed reduced trabecular bone formation and narrower zones of proliferative and hypertrophic chondrocytes in the growth plates of the long bones. Histological analyses showed that the transgenic mice had reduced cell proliferation in the proliferating zone, but lacked obvious defects in the chondrocyte differentiation. In addition, the transgenic mice with a high level of transgene expression developed spontaneous long bone fractures. In conclusion, overexpressing DPP inhibited skeletal development, suggesting that the balanced actions between the $\mathrm{NH}_{2}$ - and $\mathrm{COOH}-$ terminal fragments of DSPP may be required for normal skeletal development.
\end{abstract}

\section{Introduction}

Discovered by cDNA cloning using a mouse odontoblast cDNA library, ${ }^{1}$ the dentin sialophosphoprotein (DSPP) gene is located on human chromosome 4q21 and encodes the most prominent non-collagenous protein (NCP) in the dentin matrix. ${ }^{1,2}$ Originally thought to be dentin-specific, the expression of DSPP has also been detected in bone, ${ }^{3}$ cementum, ${ }^{4}$ cartilage,${ }^{5}$ and some non-mineralized tissues ${ }^{5,6}$ at a lower level. The importance of DSPP in biomineralization has been evidenced by human and mouse genetic studies, which showed the association of DSPP gene mutations or ablations with the mineralization defects in dentin ${ }^{7-10}$ and bone. ${ }^{11}$ However, the exact mechanism by which DSPP functions in skeletal and dental development remains largely unclear.

As a large precursor protein, DSPP is cleaved by proteases to form three major components: ${ }^{12-14}$ an $\mathrm{NH}_{2}$-terminal fragment known as dentin sialoprotein (DSP), a proteoglycan form of the $\mathrm{NH}_{2}$-terminal fragment referred to as DSP-PG, and a $\mathrm{COOH}$-terminal fragment named dentin phosphoprotein (DPP). ${ }^{15-17}$ The DSP/DSP-PG-coding sequence is on the 5' side, and the DPP is on the 3' side of the DSPP transcript. DSP and DPP were independently identified as extracellular matrix (ECM) components extracted from dentin and were discovered much earlier than DSPP. DPP was discovered in $1967^{18}$ and is the most abundant NCP in the dentin matrix. It is an unusually polyanionic protein, containing a large number of aspartic acids (Asp) and phosphoserines (Pse) in the repeating sequences of (Asp-Pse) $)_{n}$. and (Asp-Pse-Pse) $)_{n} \cdot{ }^{19,20} \mathrm{~A}$ very different protein, DSP, was discovered in $1981 ; 21$ it is a sialic acid-rich glycoprotein, with little or no phosphate. The DSP-PG component has been reported by both our group and others. ${ }^{16,17}$ DSP$\mathrm{PG}$ is present in the dentin extracellular matrix (ECM) in significant amounts, suggesting that DSP-PG may be the functional form of DSPP $\mathrm{NH}_{2}$-terminal fragment. ${ }^{22}$

The remarkable difference in chemical structures between the $\mathrm{NH}_{2}$-terminal fragment (DSP/DSP-PG) and the COOH-terminal fragment (DPP) of DSPP suggests that these various fragments may perform different functions in biomineralization ${ }^{23}$ although they are encoded by the same mRNA. Studies have shown that significant amounts of DSP/DSPPG and DPP are present in the ECM of dentin, whereas only trace amounts of the full-length form of DSPP is detectable in the dentin. ${ }^{24} \mathrm{~A}$ recent study in our laboratory has shown that blocking the proteolytic processing of DSPP leads to hypomineralization defects in dentin, similar to those observed in Dspp-deficient subjects. ${ }^{25}$ This observation strongly indicates that the proteolytic processing of DSPP into different fragments is an essential activation step in dentinogenesis. Several in vitro mineralization studies have indicated that DPP is involved in nucleation and modulation during the formation and growth of hydroxyapatite crystals. ${ }^{26-28}$ The highly negatively charged DPP is thought to play a role in promoting mineralization by binding and presenting calcium ions to collagen fibers at the mineralization
Correspondence: Yongbo Lu, Department of Biomedical Sciences and Center for Craniofacial Research and Diagnosis, Texas A\&M University Baylor College of Dentistry, 3302 Gaston Ave. Room 436, Dallas, TX 75246, USA.

Tel. +1.214.828-8277; Fax: +1.214-874-4538.

E-mail: ylu@bcd.tamhsc.edu.

Chunlin Qin, Department of Biomedical Sciences and Center for Craniofacial Research and Diagnosis, Texas A\&M University Baylor College of Dentistry, 3302 Gaston Ave. Room 400, Dallas, TX 75246, USA.

Tel. +1.214.828-8292; Fax: +1.214-874-4538.

E-mail: cqin@bcd.tamhsc.edu

Key words: Dentin sialophosphoprotein; dentin phosphoprotein; development; bone; transgenic mice; growth plate.

Contributions: HZ, YL, CQ, conception and design of the study; HZ, PL, SW, data acquisition; HZ, CL, PJ, YL, CQ data analysis and interpretation; HZ, YL, CQ, manuscript drafting; all authors have read and approved the final manuscript. YL and $\mathrm{CQ}$ contributed equally to this work.

Acknowledgments: we are grateful to Jeanne Santa Cruz for her assistance with the editing of this article. This work was supported by NIH/NIDCR Grant DE022549 to CQ and DE023365 to YL.

Conflict of interest: the authors declare no potential conflicts of interest with respect to the authorship and/or publication of this article.

Received for publication: 11 November 2015. Accepted for publication: 8 February 2016.

This work is licensed under a Creative Commons Attribution-NonCommercial 4.0 International License (CC BY-NC 4.0).

(C) Copyright H. Zhang et al., 2016

Licensee PAGEPress, Italy

European Journal of Histochemistry 2016; 60:2587 doi:10.4081/ejh.2016.2587

front. ${ }^{29,30}$ DSP does not have a significant effect on the apatite formation and growth in vitro. ${ }^{31}$ In vivo studies involving the transgenic expression of DSPP $\mathrm{NH}_{2}$-terminal fragments in the Dspp-knockout (K0) background indicated that these fragments may regulate the initiation of dentin mineralization, whereas DPP controls the maturation of dentin mineralization. ${ }^{32}$ However, the precise biological mechanisms of these fragments in mineralization have not yet been elucidated.

To examine the in vivo function of DSPP fragments in biomineralization, we first generated transgenic mice overexpressing DSPP $\mathrm{NH}_{2}$-terminal fragments and found that the transgenic expression of DSPP $\mathrm{NH}_{2}$-terminal fragments worsened the dentin defects of the 
Dspp null mice. ${ }^{33}$ In this study, we generated transgenic mice overexpressing the hemagglutinin (HA)-tagged DPP under the control of a $3.6 \mathrm{~kb}$ type I collagen (Collal) promoter (referred to as Collal-HA-DPP) in the C57BL/6J wild type (WT) mouse genetic background. We analyzed the skeletal phenotype of the Colla1-HA-DPP transgenic mice and found that these transgenic mice had a smaller body size and shorter long bone, reduced trabecular bone formation and reduced cell proliferation in the proliferating zone of growth plates compared with their WT littermates. Our findings suggest that overexpression of DPP suppresses skeletal development.

\section{Materials and Methods}

\section{Generation of HA-DPP expression construct}

DPP is the C-terminal fragment of DSPP, generated by the proteolytic cleavage of the full-length DSPP in the secretory pathway, so DPP does not have its own endoplasmic reticulum (ER)-entry signal peptide (SP). In addition, DPP does not have its own ER-exit signal peptide, as the first three amino acid residues (isoleucine-proline-valine or IPV) after the ERentry signal peptide cleavage site are required for the efficient export of DSPP from ER to the Golgi complex in the secretory pathway. ${ }^{10}$ Therefore, to ensure the proper secretion of DPP, we generated a cDNA (referred to as HADPP) that encoded a protein in which the mouse DPP (containing 494 amino acid residues) was fused to the first 25 amino acids of DSPP (including the 17 amino acid residues of the ER-entry signal peptide and the first eight amino acid residues of mature DSPP) (Figure 1A). In addition, a hemagglutinin (HA) tag was inserted at the amino-terminal end of DPP to allow detection of the transgenic DPP protein. Since specific antibodies against DPP are not available, tagging the HA epitope to DPP allows us to employ anti-HA antibodies to detect DPP in the cell lines and the transgenic animals. The HA-DPP cDNA was generated by a combination of DNA synthesis and polymerase chain reaction (PCR), and cloned downstream of a cytomegalovirus (CMV) promoter in pCDNA3 expression vector (Invitrogen, Grand Island, NY, USA). The HADPP cDNA was confirmed by DNA sequencing.

\section{Generation of transgenic mice expressing HA-DPP}

We previously generated transgenic mice expressing normal DSPP under the control of a 3.6/1.6 kb Collal promoter/intron fragment and demonstrated that normal DSPP fully rescued the dentin defects of Dspp-null mice. ${ }^{25}$ To determine the in vivo function of DPP, we generated transgenic mice expressing HA-DPP under the control of the same $3.6 / 1.6 \mathrm{~kb}$ Collal promoter/intron fragment (referred to as Colla1-HA-DPP). Briefly, the HA-DPP coding sequence was cloned downstream of the 3.6/1.6 kb Collal promoter/intron fragment followed by the SV40 polyadenylation signal in the pBC-KS vector. The Colla1-HA-DPP transgene was released by SacII and SalI restriction endonucleases, separated from the vector backbone by agarose gel electrophoresis, and purified using Elutip-D columns (Whatman Schleicher \& Schuell Bioscience, Inc., Keene, $\mathrm{NH}$, USA). The transgenic mice were generated on a C57BL/6J genetic background by pronuclear injection at the Transgenic Technology Center of the University of Texas Southwestern Medical Center, Dallas, TX, USA. Founder mice were identified by PCR analysis of genomic DNA extracted from tail biopsies using the following two sets of primers specific for the transgene: set 1 , forward primer, 5 GATGGTGACAGCAAGTCTGG-3', located on the Collal intron fragment; and reverse primer, 5 TGTCCAAACTCATCAATGTATCT-3', located on the HA-DPP coding sequence. Set 2, forward primer, 5'-TGGTGGTGCAAATCAAAGAA-3', located on DPP coding sequence, and reverse primer, 5'-CTGTCACTGTCACCATCACCATTAC3 , located on SV40 polyadenylation signal. The size of the PCR product was $\sim 200$ bp for the first set of primers, and $\sim 500$ bp for the second set of primers.

Both female and male transgenic mice were included in the experiments since there was no apparent phenotypic difference between genders. The age- and sex-matched WT littermates were used as control mice. All animal protocols were approved by the Animal Welfare Committee of the Texas A\&M University Baylor College of Dentistry.

\section{Cell culture and transfection}

Human embryonic kidney cells (HEK-293 EBNA) were cultured as described previously. ${ }^{34}$ Briefly, HEK-293 EBNA cells were cultured in Dulbecco's Modified Eagle's Medium (DMEM) supplemented with $10 \%$ fetal bovine serum (Invitrogen). For transfection, HEK-293 EBNA cells were transiently transfected with a construct expressing HA-DPP or pCDNA3 empty vector with X-tremeGENE 9 DNA transfection reagent (Roche, Indianapolis, IN, USA), according to the manufacturer's instructions. The transfection medium was replaced with serum-free medium 16-18 h after transfection and then the transfected cells were cultured for an additional $48 \mathrm{~h}$. The conditional medium was collected and analyzed for HA-DPP-related proteins by Western immunoblotting with an anti-HA monoclonal antibody (Covance Inc., Dallas, TX, USA) at a dilution of 1:1000.

\section{RT-PCR and qRT-PCR}

Total RNAs were extracted from the long bones of 4-week-old Colla1-HA-DPP transgenic mice and WT mice using an RNeasy mini kit (QIAGEN, Germantown, MD, USA). The RNAs (1 $\mu \mathrm{g}$ per sample) were then reversetranscribed into cDNAs using the QuantiTect Reverse Transcription Kit (QIAGEN). RT-PCR was performed to examine the expression of the exogenous DPP transgene in bone. The primers used for RT-PCR were: forward, 5 GATGGTGACAGCAAGTCTGG-3' (in the C-terminal region of DPP) and reverse, 3 -TGTCCAAACTCATCAATGTATCT (in SV40 poly A tail). The housekeeping gene, glyceraldehyde-3phosphate dehydrogenase (Gapdh) was used as the internal control. The reaction condition was: $95^{\circ} \mathrm{C}$ for $4 \mathrm{~min}, 60^{\circ} \mathrm{C}$ for $30 \mathrm{~s}$ and $72^{\circ} \mathrm{C}$ for $30 \mathrm{~s}, 35$ cycles. Real time RT-PCR was performed using Go Tag ${ }^{\circledR}$ qPCR Master Mix System (Promega, Madison, WI, USA) and CFX96 Real-Time PCR Detection System (BioRad, Hercules, CA). The qRT-PCR condition was: initial denaturation at $95^{\circ} \mathrm{C}$ for $2 \mathrm{~min}$, followed by 40 cycles of $95^{\circ} \mathrm{C}$ for $30 \mathrm{~s}, 60^{\circ} \mathrm{C}$ for 1 min. The DPP primers for qRT-PCR were designed to amplify both endogenous DSPP and transgenic DPP transcripts, and they were: forward primer, 5 - CAGCAAGGATAGCAGTTCTGA-3 ; and reverse primer, 5 -TGTCACTGCCTTCACTGTCAC-3 . The housekeeping gene, Gapdh, was used as the internal control. The primers for Gapdh were: forward primer, 5'GAAGCCCATCACCATCTTC-3'; and reverse primer, 5'- GTTCACACCCATCACAAACA-3'. The data were analyzed using the $2^{-}{ }_{\mathrm{T}}$ Method, The mRNA level in the WT mice was set as one, and the mRNA levels of transgenic mice were calculated relative to that in the WT mice.

\section{Extraction of NCPs and detection of HA-DPP-related proteins}

Non-collagenous proteins (NCPs) were extracted from long bones of 4-week-old DPP transgenic and WT mice using a protocol described previously. ${ }^{24}$ Equal amounts of samples were loaded onto 4-12\% SDS-PAGE gel. Western immunoblotting was performed to identify the HA-DPP-related proteins in the long bone and incisor extracts, using an antiHA monoclonal antibody (Covance Inc.) at a dilution of 1:1000. The blots were incubated in HRP-conjugated goat anti-mouse IgG secondary antibody (Santa Cruz, Dallas, TX) at a dilution of 1:5000, followed by incubation in a chemiluminescent substrate for $3 \mathrm{~min}$ and subsequent exposure to X-ray films.

\section{Plain X-ray radiography and high- resolution microcomputed tomog- raphy $(\mu \mathrm{CT})$}

Both the Colla1-HA-DPP transgenic mice 
and WT mice or long bones dissected from these mice at the ages of 3 and 12 weeks were analyzed using a Faxitron MX-20 Specimen Radiography System with a digital camera attached (Faxitron X-ray Corp., Buffalo Grove, IL, USA). The femurs from 3-week-old mice were further scanned using a Scanco $\mu$ CT35 imaging system ( $\mu$ CT35, Scanco Medical, Bassersdorf, Switzerland) with a slice increment of $7 \mu \mathrm{m}$ at medium resolution to assess the overall shape and structure. The threedimensional (3-D) structure was constructed at the threshold of 150 . Following this evaluation, a high-resolution scan in $3.5 \mu \mathrm{m}$ slice increments was performed to examine the midshaft cortical bone parameters and the distal metaphyseal trabecular bone microarchitecture of the femurs. The morphometric parameters analysis was performed using the built-in software of the $\mu$ CT system. The cortical bone volume fraction (bone volume/total volume, \%) and material density were obtained from 231 slices at the mid-shaft of the femurs at a threshold of 283 . The trabecular bone volume fraction and material density were measured on a set of 200 sections underneath the growth plate at a threshold of 250 . The various thresholds used to segment bone from soft tis- sues were specimen-specific. Each threshold was chosen based on visual comparisons between slice-wise 2D unsegmented and segmented images, and a fixed threshold was applied for the same sample type. The data acquired from the high-resolution scans of four samples per group were used for the quantitative analysis.

\section{Histology analysis}

For histologic analysis, the bone samples were fixed in freshly prepared 4\% paraformaldehyde in phosphate-buffered saline $\left(\mathrm{pH} \mathrm{7.4)}\right.$ at $4^{\circ} \mathrm{C}$ overnight and then decalcified in $15 \%$ ethylenediaminetetraacetate (EDTA) solution (pH 7.4) at $4{ }^{\circ} \mathrm{C}$ for $5 \sim 14$ days depending on the ages of the animals. The samples were embedded in paraffin using standard histological procedures. The tissue blocks were cut into 5 - $\mu \mathrm{m}$ thick serial sections and were then used for Hematoxylin and Eosin (H\&E) staining, Safranin 0 staining, toluidine blue staining or immunohistochemistry (IHC). For IHC analyses, monoclonal anti-HA antibody (1:2000) was used to recognize the HA epitope tagged to DPP protein. The IHC experiments were carried out using the M.O.M. kit and the DAB kit
(Vector Laboratories, Burlingame, CA, USA, USA) according to the manufacturer's instructions. For BrdU analysis, the animals at 3-week of age were injected with BrdU (5-Bromo-2'deoxyuridine, $100 \mu \mathrm{g} / \mathrm{g}$ mouse, i.p.; SigmaAldrich, St. Louis, M0, USA) twice (the first injection was 24 hours and the second was 2 hours before sacrifice). The long bones were collected and processed for paraffin sectioning as described above. The BrdU-labeled cells were detected using a BrdU staining kit (Invitrogen) according to the manufacturer's instruction. To quantify cell proliferation, images of the growth plate areas were captured under a 20x objective, BrdU-positive nuclei and total nuclei in the zone of proliferative chondrocytes were counted. The percentages of BrdU-labeled cells among the total proliferative chondrocytes were calculated as a measure of cell proliferation.

In situ hybridization was carried out to assess the expression of type II collagen ( $\mathrm{Col}$ $I I)$ and type $\mathrm{X}$ collagen $(\mathrm{Col} X)$ in 10-day-old long bone samples from the Collal-HA-DPP transgenic mice and their WT littermates as described previously. ${ }^{35}$ Briefly, the RNA probes were labeled with digoxigenin (DIG) using a RNA Labeling Kit (Roche) according to the
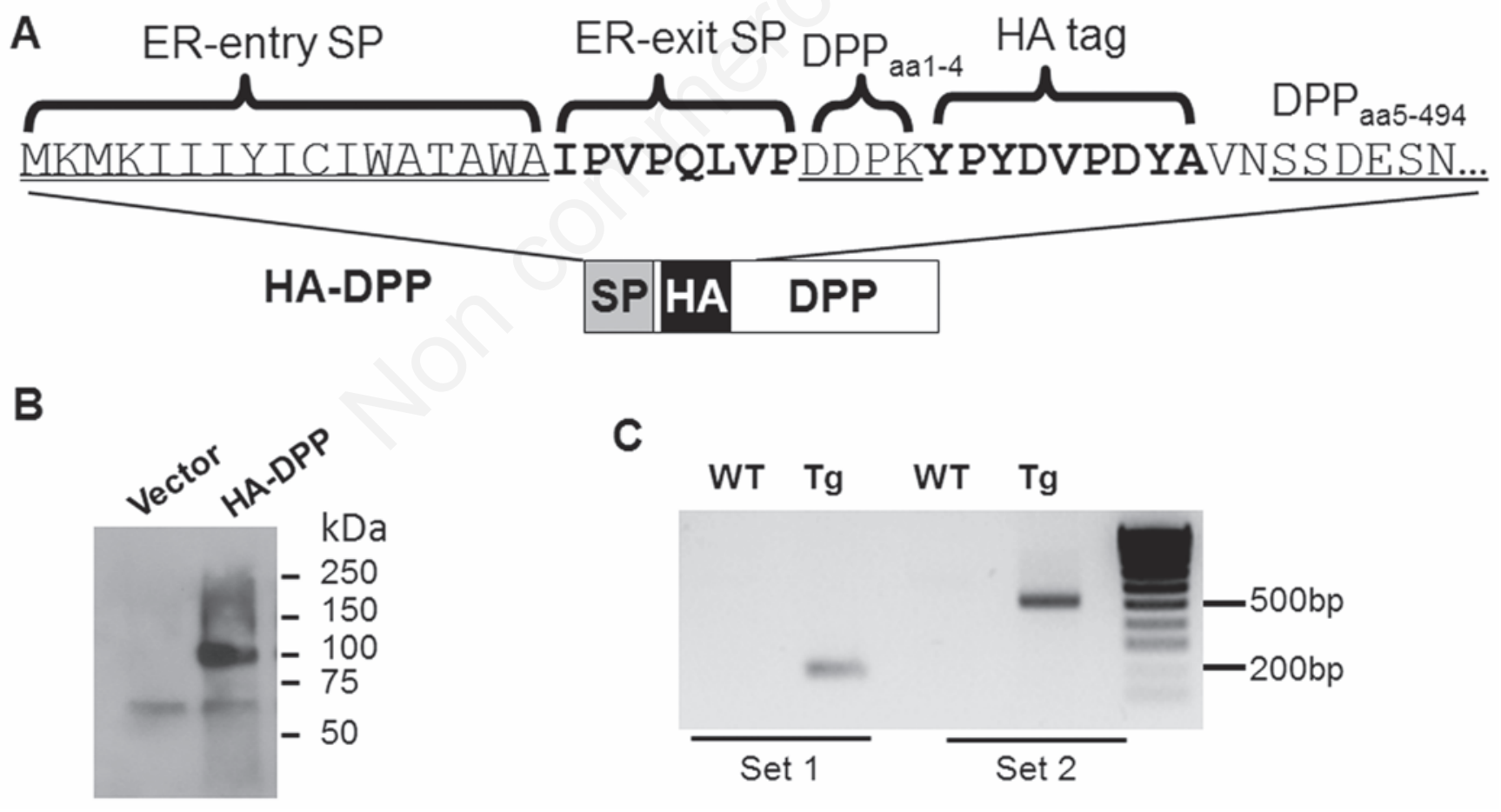

B

Figure 1. Generation of HA-DPP expression construct. A) The HA-DPP expression construct was designed to encode a protein that included the 17 amino acid residues of mouse DSPP ER entry signal peptide, the first eight amino acid residues of mature DSPP (including the IPV motif) and the 494 amino acid residues of mouse DPP; an HA tag was inserted at the NH2-terminal end of DPP as indicated. B) Expression of HA-DPP in HEK-293 EBNA cells; Western immunoblotting was performed with anti-HA antibody to detect the secreted HA-DPP protein in the conditioned medium collected from the cells transfected with pCDNA3-HA-DPP expression construct. C) Genotyping strategy; the transgenic ( Tg) mice were genotyped by PCR using 2 different sets of primes specific for the transgene, giving rise to a $-200 \mathrm{bp}$ fragment and $-500 \mathrm{bp}$ fragment, respectively. 
manufacturer's instruction. DIG-labeled RNA probes were detected by an enzyme-linked immunoassay with a specific anti-DIG-alkaline phosphatase antibody conjugate (Roche) and a VECTOR red alkaline phosphatase substrate (Vector Laboratories, Burlingame, CA, USA), which produced a red color for positive signals. The sections were counterstained with methyl green.
Alcian blue/alizarin red staining of the skeleton

Alcian blue/alizarin red staining was performed to analyze the overall skeletal and mineralization defects as described previously. ${ }^{36}$ Briefly, 16-day-old Colla1-HA-DPP transgenic mice and control mice were sacrificed, skinned, eviscerated and fixed for three days in $95 \%$ ethanol. They were then stained with alcian blue for cartilage and alizarin red for bone.

\section{Statistical analysis}

The data were expressed in terms of mean \pm SD (standard deviation). Two-group data were analyzed with an unpaired Student's $t$-test. $\mathrm{P} \leq 0.05$ was considered as the statistically significant difference for all comparisons.

A

$\begin{array}{lllllll}1 & 2 & 3 & 4 & 5 & 6 & \text { WT }\end{array}$

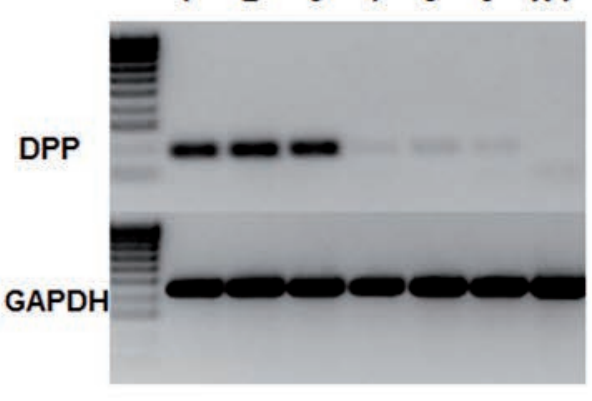

B

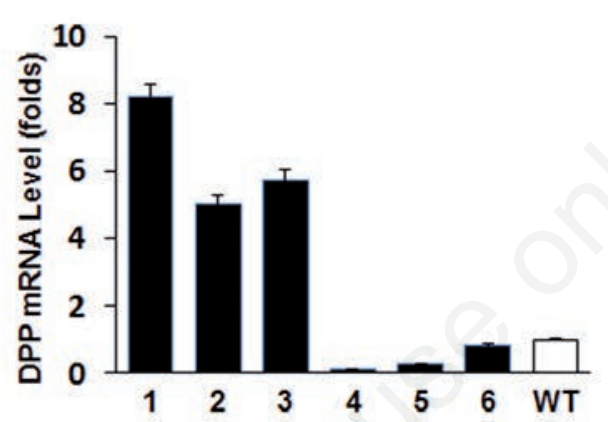

C

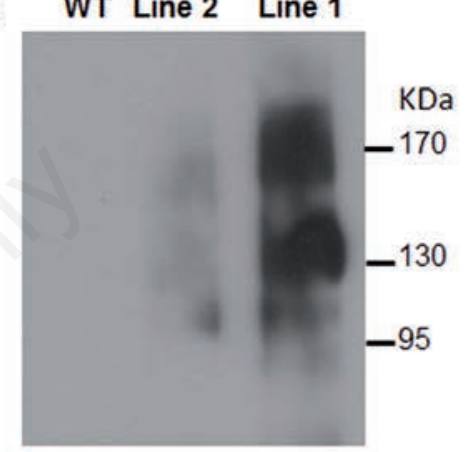

D
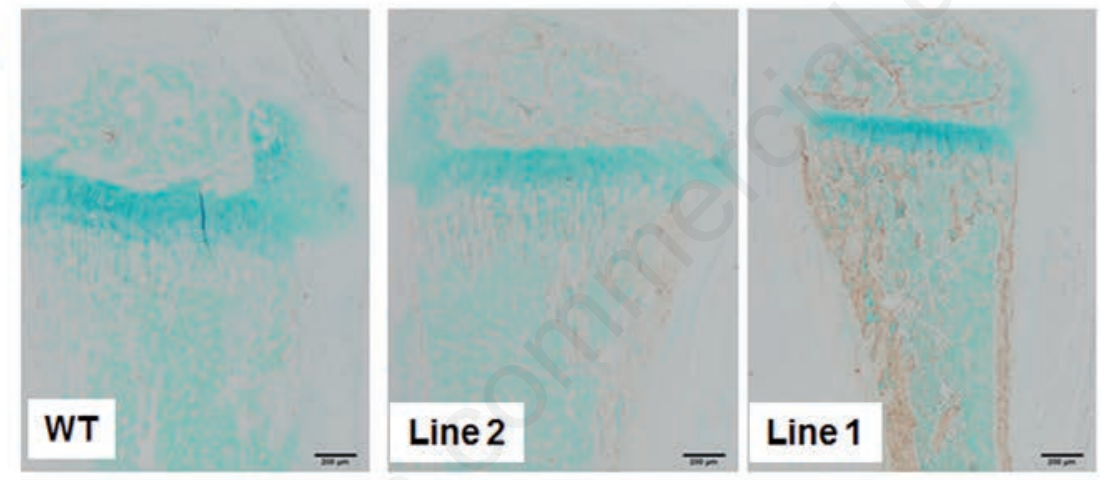

E
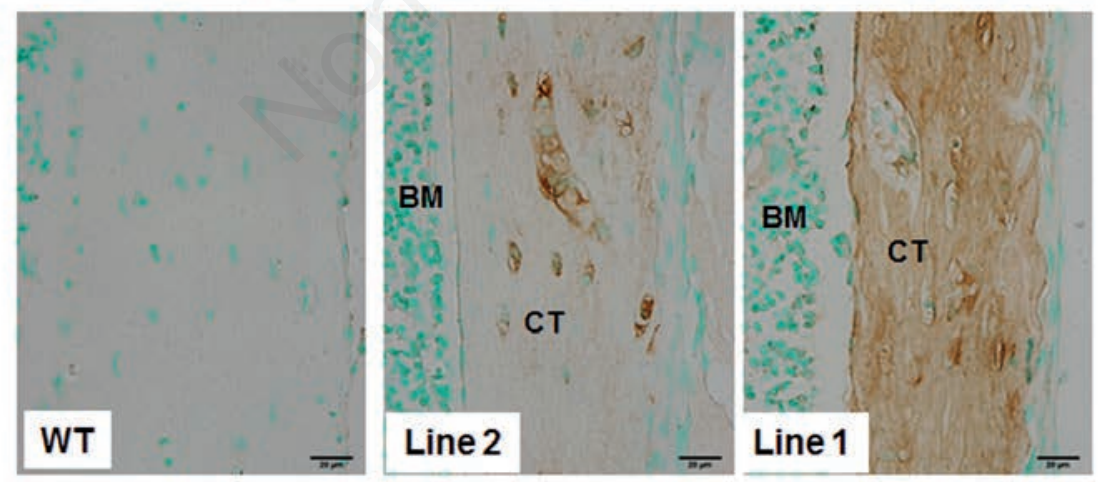

Figure 2. Expression of HA-DPP in the long bones of Col1a1-HA-DPP transgenic mice. A) RT-PCR was performed to specifically detect transgenic DPP transcripts using total RNAs extracted from the long bones of 4-week-old transgenic (Tg) and wild type (WT) mice; lines 1, 2 and 3 showed a strong expression band. B) Real time PCR analysis showed the relative expression level of DPP mRNA in six Tg lines (line1-6); the mRNA expression in WT samples was set as 1 and the fold changes in the six Tg lines were calculated relative to that of the WT mice; the line 1 mice showed the highest mRNA level (approximately 7-fold higher than that of the endogenous gene expression in the WT mice). C) Western immunoblotting analyses was carried out with an anti-HA antibody to detect transgenic HA-DPP protein in the 4-week-old long bone extracts of WT, line 2 and line 1 Tg mice; HA-DPP protein was detected in the line 1 and line 2, but not in the WT mice. D) Immunohistochemical staining of HA-DPP in the tibiae of 3-week-old mice. Note the strong HA-DPP protein signals in the line $1 \mathrm{Tg}$ mice, compared to those in the line $2 \mathrm{Tg}$ mice; scale bars: $200 \mu \mathrm{m}$. E) Higher magnification image showed that the HA-DPP protein was mainly found in the long bone matrix. BM, bone marrow, CT, cortex; scale bars: $20 \mu \mathrm{m}$. 


\section{Results}

\section{Generation of Col1a1-HA-DPP transgenic mice}

To confirm the expression and secretion of HA-DPP, the HA-DPP-expressing construct was transiently transfected into HEK-293 EBNA cells. Western-blotting analysis with the antiHA antibody showed that HA-DPP protein was readily detected in the conditioned medium harvested from the cells transfected with HADPP-expressing construct (Figure 1B), suggesting the successful expression and secretion of the HA-DPP protein.

The Colla1-HA-DPP transgenic mice were then generated to determine the in vivo function of DPP. The founder mice were identified by PCR analysis of tail genomic DNA (Figure 1C). A total of fifteen Collal-HA-DPP founders were obtained and bred with $\mathrm{C} 57 \mathrm{BL} / 6 \mathrm{~J}$ wild type mice to establish transgenic lines for further analysis. To our surprise, six founders died within 6 months without any obvious gross defects; one founder failed to produce any pups; and two founders failed to pass the transgene on to their offspring. Therefore, only 6 founders produced F1 transgenic mice and were analyzed in this study.

\section{Expression of Col1a1-HA-DPP transgene in bone}

The transgenic expression of HA-DPP in bone was first confirmed at the transcript level by RT-PCR and qRT-PCR, using total RNAs extracted from the long bones of the six Collal-HA-DPP transgenic lines (Figure 2 A,B). The RT-PCR primers were designed specifically to detect the transgenic DPP transcripts, but not the endogenous DSPP transcripts. As shown in Figure 2A, the lines 1, 2 and 3 showed a strong DPP expression band, whereas the lines 4, 5 and 6 had very weak bands (Figure 2A). The relative expression level of the DPP transgene in the long bones from the six lines of transgenic mice was determined using qRT-PCR analyses with primers that amplified both transgenic DPP transcripts and endogenous DSPP transcripts (Figure 2B). Consistent with RT-PCR results, the lines 1, 2 and 3 had higher levels of transgene expression compared to the wild type mice. In contrast, the lines 4, 5 and 6 showed extremely low levels of transgene expression, suggesting that the transgene was barely active in the lines 4,5 and 6 .

The transgene expression in the line 1 and line 2 mice was further confirmed at the protein level by WB and IHC analyses using the anti-HA monoclonal antibody. The line 3 was not analyzed because we failed to obtain any more transgenic progenies from the founder 3 . Western immunoblotting analysis was performed on NCP extracted from the long bones of the lines 1 and 2 and WT mice. As shown in Figure 2C, HA-DPP related proteins were detected in both lines 1 and 2 samples but not in the WT sample. IHC analysis showed that the HA-DPP protein signals were mainly localized in the matrices of the long bones in both lines 1 and 2 mice (Figure 2 D,E). Both WB and IHC analyses revealed a higher level of HADPP related proteins in the line 1 transgenic mice, compared with the line 2 mice.

\section{Skeletal defects associated with the transgenic expression of DPP}

Having confirmed the transgene expression in the lines 1 and 2, we next analyzed the skeletal phenotype of these two transgenic lines. The line 2 transgenic mice were smaller compared with their WT littermates as demonstrated by plain X-ray radiography at 4 wks of age (Figure $3 \mathrm{~A}$ ) and body weight monitoring from postnatal 3 weeks to postnatal 9 weeks (Figure 3B). Plain X-ray radiography showed that the radiopacity of the femurs/tibiae from 3 - and 12-wk-old line 2 mice appeared to be similar as those from the WT littermates (Figure $3 \mathrm{C}$ ). The $\mu \mathrm{CT}$ images demonstrated that the femurs from 3 -wk-old line 2 mice were shorter and had reduced trabecular bone in the distal metaphysis area, compared with those from the WT femurs (Figure 3D). The quantitative $\mu \mathrm{CT}$ analysis confirmed that the femurs of the line 2 transgenic mice were significantly shorter than the WT mice (Table 1). In addition, the distal growth plate thickness of femur in the line 2 mice showed a significant $50 \%$ reduction compared to that in the WT control mice (Table 1). Although the ratio of BV/TV was slightly increased in the cortical bone, it was significantly reduced in the trabecular bone in the line 2 transgenic mice (Table 1). However, there was no significant difference in other bone parameters, including the cortical and trabecular bone mineral density as well as the trabecular bone number, thickness and separation between the line 2 and WT mice (Table 1). Furthermore, we also analyzed several bone matrix proteins, including bone sialoprotein (BSP), osteopontin (OPN), biglycan and dentin matrix protein 1 (DMP1), by immunohistochemistry and did not find apparent difference between the line 2 transgenic and WT mice (data not shown).

Consistent with the high level of transgene expression, the line 1 transgenic mice had much severe skeletal defects. In fact, we never obtained any F2 transgenic mice from this line, which was most likely because the F1 mice had prominent dwarfism and severe long bone defects. Plain x-ray radiography showed that the line 1 transgenic mice were remarkably smaller than their WT littermates at 4 wks of age (Figure 3A). Some line 1 mice developed spontaneous long bone fracture (Figure 3C). Few of the line 1 transgenic mice (F1) could survive to the adult age, but X-ray radiography showed that they had poorly formed long bones (Figure 3C). Alizarin red/alcian blue staining of the skeletons of 16-day-old mice also showed that the line 1 transgenic mice had much smaller skeletons (Figure 4A), abnormal elbow joint in the forelimb (most likely due to a previous bone fracture in the ulna near the

Table 1. Quantitative $\mu \mathrm{CT}$ analysis of femur midshaft cortical bone and distal metaphysis trabecular bone.

\begin{tabular}{lcc} 
& WT & line 2 \\
Femur length (mm) & $10.070 \pm 0.286$ & $8.354 \pm 0.559^{* *}$ \\
Distal growth plate thickness (mm) & $0.218 \pm 0.027$ & $0.101 \pm 0.010^{* * *}$ \\
\hline Midshaft cortical bone parameters & & $0.204 \pm 0.030$ \\
BV/TV & $0.163 \pm 0.018$ & $763.159 \pm 18.258$ \\
Bone mineral density (mg HA/cm $\left.{ }^{3}\right)$ & $776.138 \pm 26.343$ & $2.365 \pm 0.178$ \\
Trabecular bone parameters & & $0.022 \pm 0.001$ \\
Tb.N. (mm $\left.{ }^{-1}\right)$ & $2.602 \pm 0.084$ & $0.426 \pm 0.033$ \\
Tb.Th (mm) & $0.024 \pm 0.003$ & $0.011 \pm 0.003 *$ \\
Tb.Sp (mm) & $0.392 \pm 0.015$ & $647.288 \pm 19.213$ \\
BV/TV & $0.020 \pm 0.006$ & \\
Bone mineral density (mg HA/cm $\left.{ }^{3}\right)$ & $630.761 \pm 19.946$ &
\end{tabular}

BV, bone volume; TV, total (tissue) volume; Tb.N., trabecular bone number; Tb.Th, trabecular bone thickness; Tb.Sp, trabecular bone separation. Values are expressed as mean \pm SD from four 3-weekold mice per group. ${ }^{*} \mathrm{P}<0.05 ; * * \mathrm{P}<0.01 ; * * * \mathrm{P}<0.001$. 


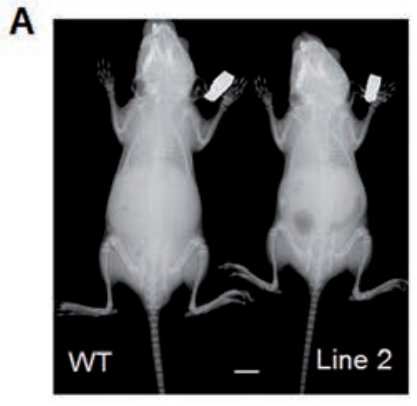

C
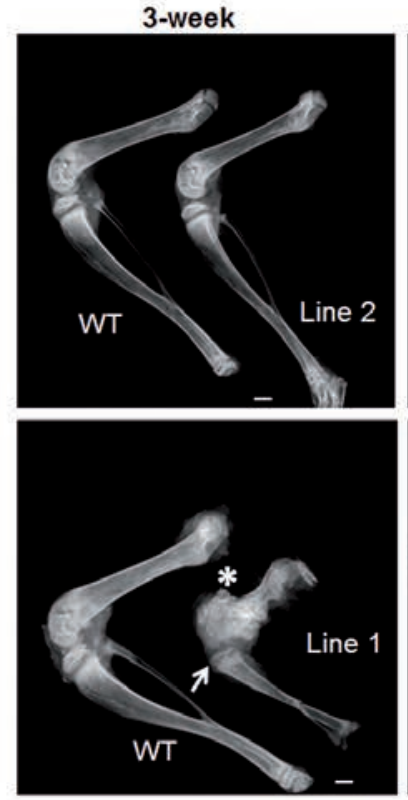

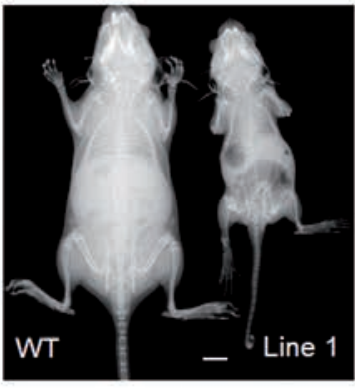

12-week
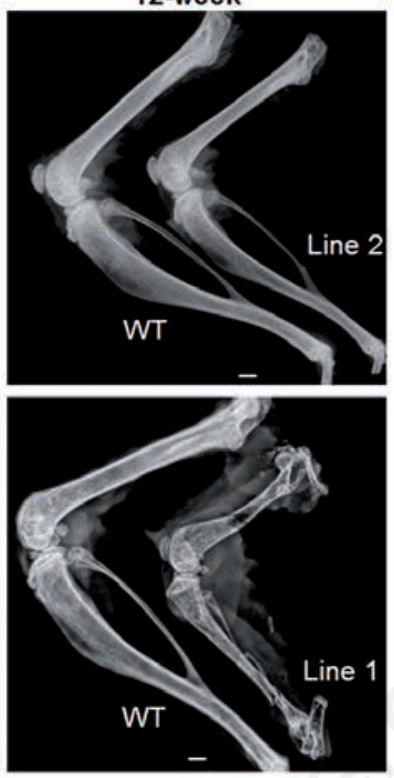

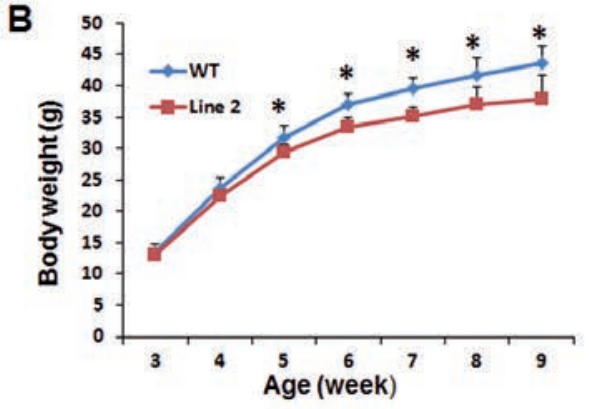

D

WT Line $2 \quad$ WT
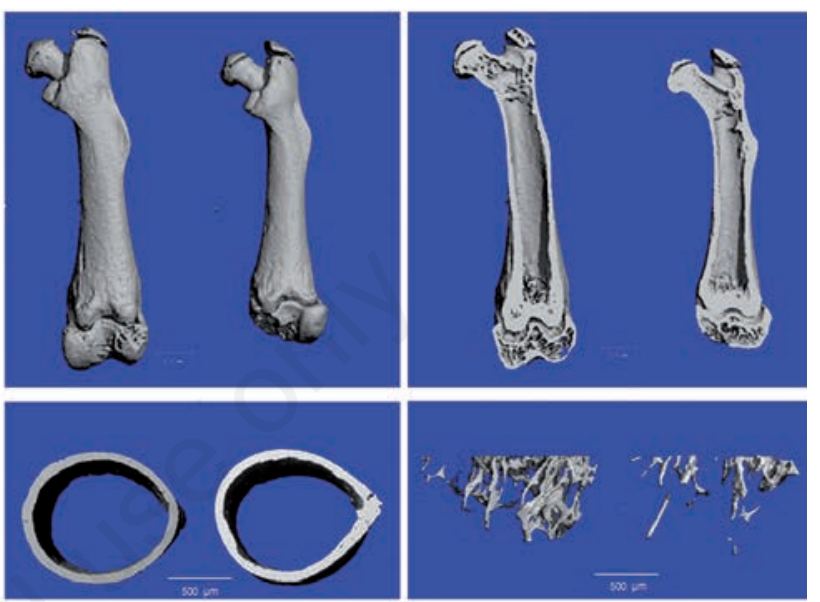

Figure 3. Skeletal defects of Col1a1-HA-DPP transgenic mice. A) Plain X-ray radiographs of 3-week-old Tg mice showed that both the line 2 and line 1 mice were smaller, compared with the WT littermates; scale bars: $5 \mathrm{~mm}$. B) Body weight monitoring of the male line 2 Tg mice and WT littermates from postnatal 3 weeks to postnatal 9 weeks; note that the line $2 \mathrm{Tg}$ mice showed significantly lower body weight compared to the WT littermates, starting from 5-wk of age; ${ }^{*} \mathbf{P}<0.05, n=4$. C) Plain X-ray radiographs of the hind limbs at different ages; the femurs and tibiae of both the line 2 and line $1 \mathrm{Tg}$ mice were shorter than their WT littermates; the femur of the line 1 Tg mice developed spontaneous fracture (asterisk) at 3-wk of age; scale bars: $1 \mathrm{~mm}$. D) Representative $\mu \mathrm{CT}$ images of the entire femurs (upper left panel), the coronal sections of the femurs (upper right panel), the femoral midshaft (lower left panel) and the femoral distal metaphysis (lower right panel) from 3-week-old line $2 \mathrm{Tg}$ mice and their WT littermates; upper scale panel bars: $1 \mathrm{~mm}$; lower panel scale bars: $500 \mu \mathrm{m}$.

A

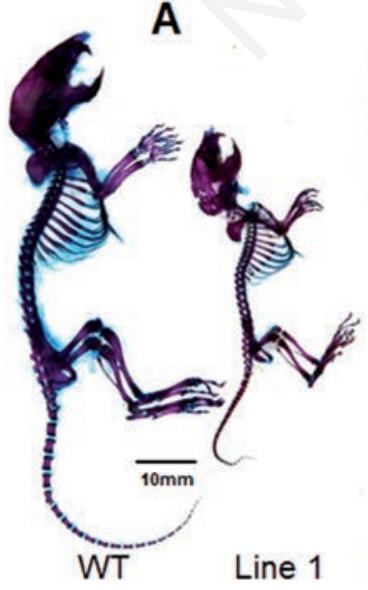

B

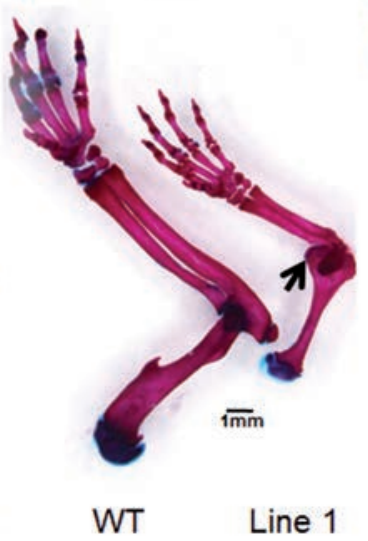

C

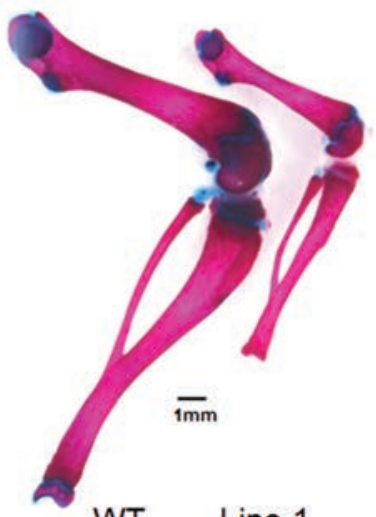

D

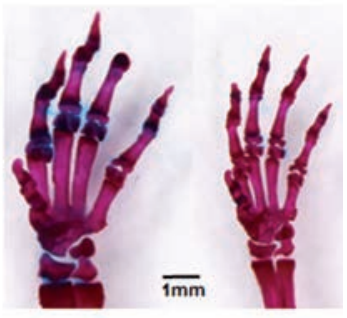

$$
\text { WT Line } 1 \text { WT Line } 1
$$

Figure 4. Alcian blue and alizarin red staining of the skeletons of 16-day-old WT and line $1 \mathrm{Tg}$ mice. The Tg mice had much smaller skeletons, compared with WT littermates (A), and showed abnormal elbow joints (arrow) in the forelimb (B), underdeveloped epiphysis in both femur and tibia (C) and less cartilage (less blue staining) in the growth plate area (C,D). Scale bars: A) $10 \mathrm{~mm}$; B-D) 1 mm. 
elbow joint) (Figure 4B), shorter femurs, tibia (Figure 4C), shorter phalanges (Figure 4B) and less cartilage in the growth plate area (Figure $4 \mathrm{C}, \mathrm{D}$ ).

Collectively, these results demonstrated that the transgenic expression of DPP inhibited long bone growth and endochondral bone formation and that such effect became more severe as the level of transgene expression increased.

\section{Transgenic expression of DPP led} to reduced cell proliferation in the growth plate

Next, we determined whether the short bone length observed in the Collal-HA-DPP transgenic mice was due to the defects in the growth plate. Consistent with $\mu \mathrm{CT}$ analysis, $\mathrm{HE}$ staining of the sagittal sections of the tibia showed that both lines 1 and 2 transgenic mice displayed narrower zones of proliferative and hypertropic chondrocytes at 3 wks of age (Figure 5A). However, as the epiphysis and metaphysis begin to fuse at 12 wks of age, the width of the growth plates of the transgenic and WT mice did not appear to be different (Figure 5B). Therefore, we examined whether there was a defect in cell proliferation in the growth plates of the line 2 transgenic mice, as we could not obtain more samples from the

\section{WT}
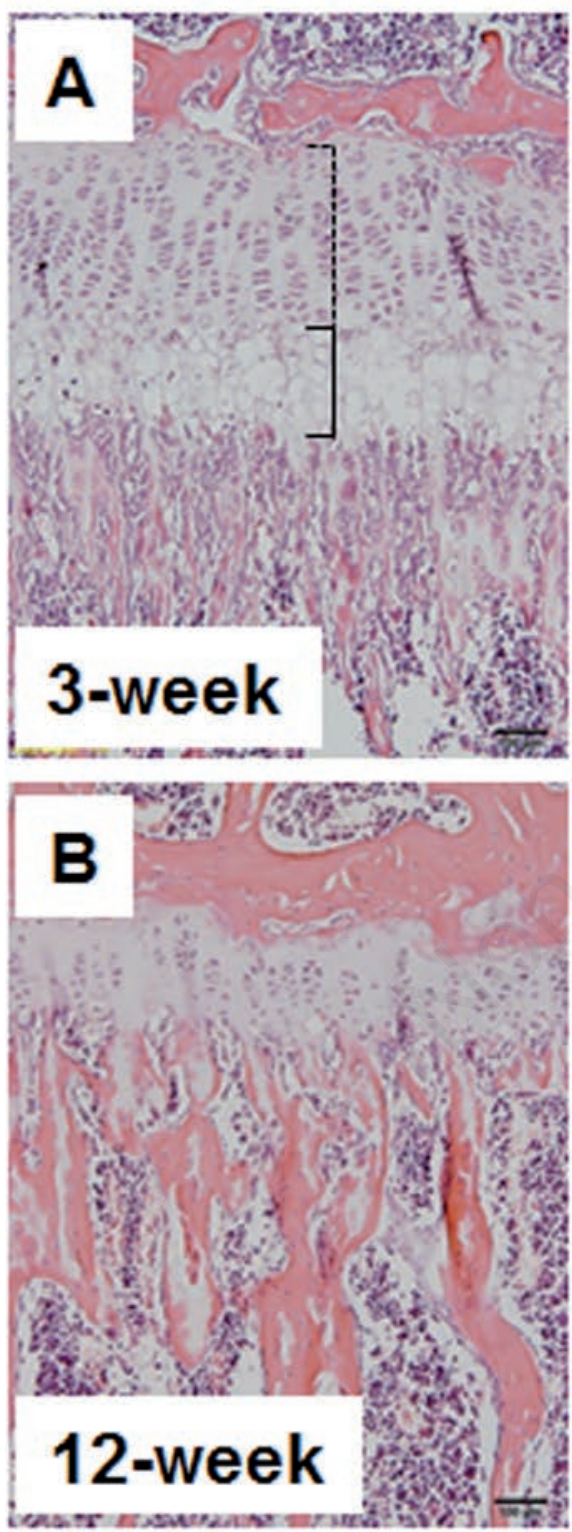

Line 2
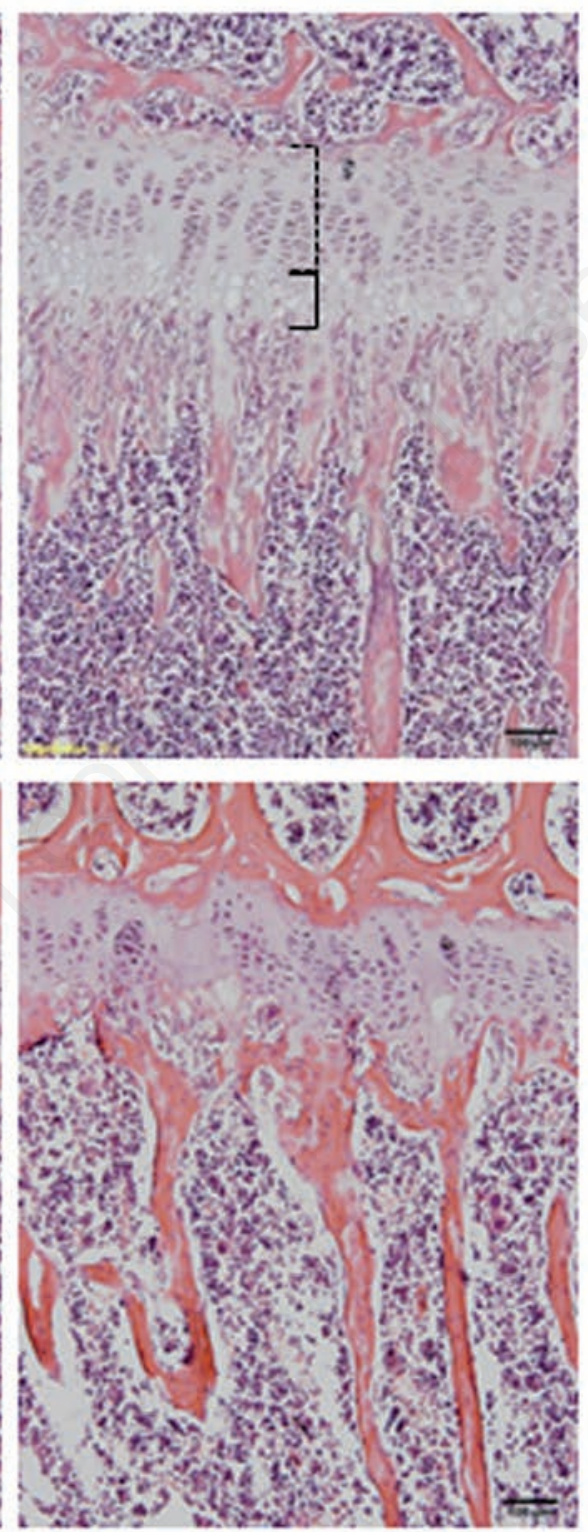

Line 1
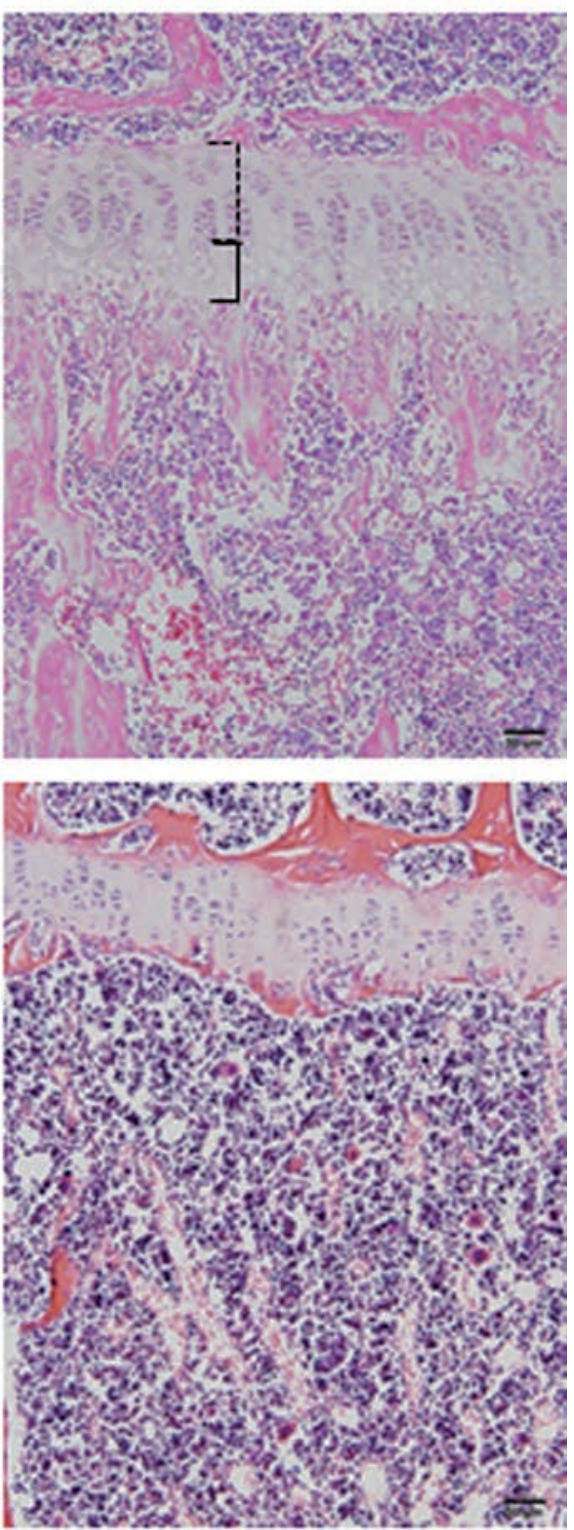

Figure 5. Growth plate defects of Colla1-HA-DPP transgenic mice. HE staining of the sagittal sections of tibia growth plate areas at 3-wk of age (A) and 12-wk-of age (B). At 3-wk of age, both line 1 and line 2 mice showed a narrower zone of hypertropic chondrocytes and narrower zone of proliferative chondrocytes compared to the WT mice. At 12-wk of age, the width of the growth plate did not show obvious difference between the Tg and WT mice. Scale bars: $100 \mu \mathrm{m}$. 
line 1 founder. As shown in Figure 6, the ratio of BrdU-positive cells to the total number of cells in the proliferative zone of the growth plate was significantly reduced in the line 2 transgenic mice compared to that in the WT littermates, suggesting a reduced cell proliferation as a result of transgenic expression of HADPP. We then determined whether there was a defect in the chondrocyte differentiation in the growth plate. We analyzed the expression of chondrocyte differentiation markers, including type II collagen (Col II, a marker for the proliferating chondrocytes) and type X collagen (Col $\mathrm{X}$, a marker for the hypertrophic chondrocytes) in the growth plates of 10-day-old line 2 transgenic mice and their WT littermates by in situ hybridization analyses. As shown in Figure 7A$\mathrm{B}$, the signal intensities of both $\mathrm{Col}$ II and $\mathrm{Col}$
$\mathrm{X}$ mRNA in the line 2 transgenic mice were comparable to those in the WT mice. In addition, we analyzed the proteoglycan expression in the growth plate of 3-wk-old line 2 transgenic mice and their WT littermates by both safranin 0 and toluidine blue stainings. Safranin 0 stains cartilage red while toluidine blue stains cartilage blue. As shown in Figure 7 C-D, although both stainings revealed a narrower growth plate in the line 2 transgenic mice, the staining intensities appeared to be similar in the line 2 transgenic mice and the WT mice. Taken together, these findings suggested that the growth plate defects in the Colla1-HA-DPP transgenic mice were mainly due to the reduced cell proliferation, but was not due to a defect in the chondrocyte differentiation.

\section{Discussion}

In the ECM of dentin and bone, DSPP is mainly present as the processed DSP, DSP-PG and DPP. DPP is very unique because it is a highly phosphorylated and acidic protein. To determine the function of DPP in vivo, we generated Collal-HA-DPP transgenic mice expressing DPP in the osteoblast/osteocyte lineage under the control of a $3.6 \mathrm{~kb}$ type I collagen promoter. These transgenic mice had a smaller body size, shorter long bones and decreased bone formation. Furthermore, we found that these skeletal defects became more severe as the level of the Colla1-HA-DPP transgene expression increased.

The Colla1-HA-DPP transgenic mice are a
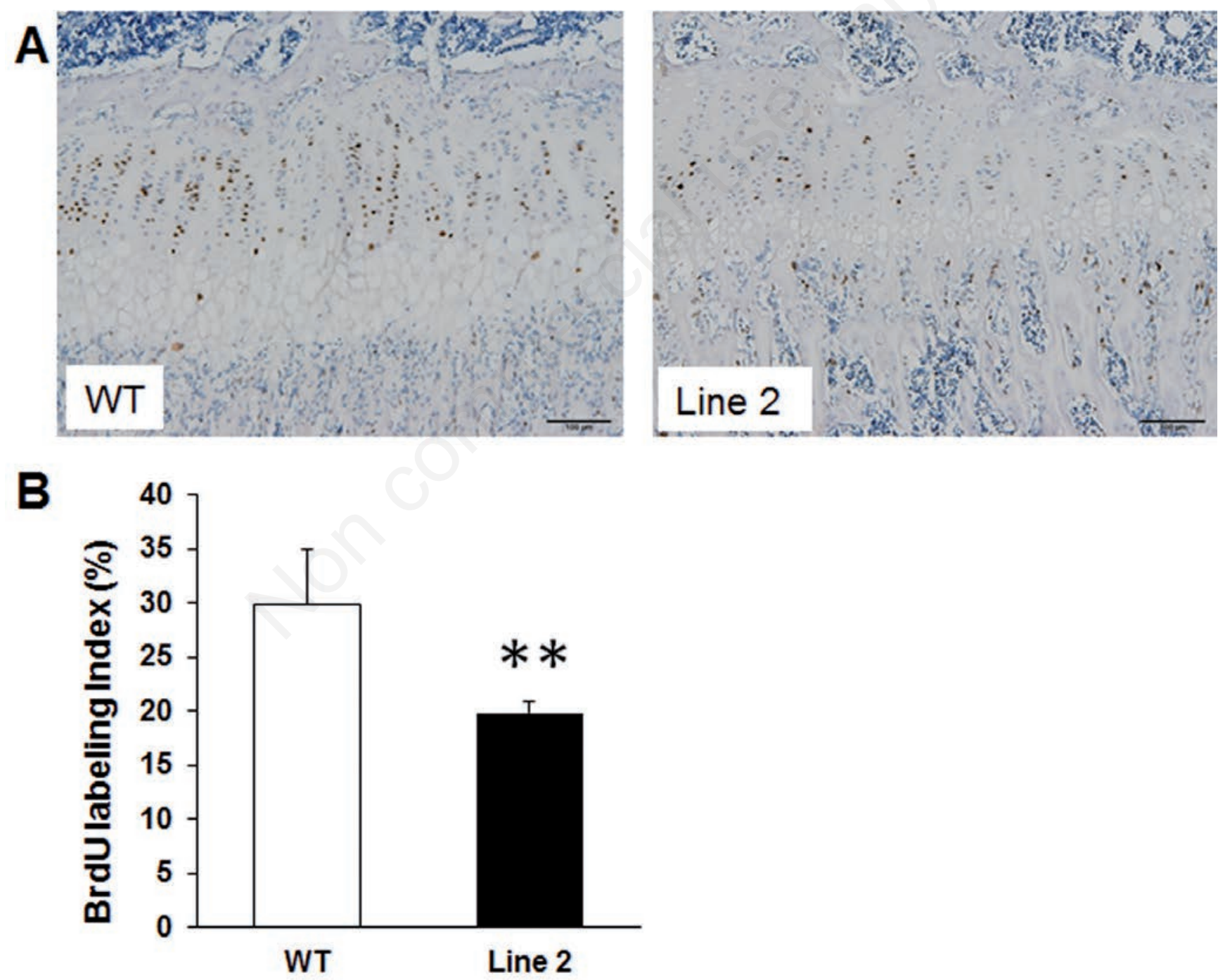

Figure 6. Cell proliferation in the growth plates of the line 2 transgenic mice. A) BrdU immunostaining revealed that the BrdU-positive cells (signal in brown) were fewer in the proliferative zone of the growth plates in the line $2 \mathrm{Tg}$ mice than those in the WT mice. B) The quantified data showed that BrdU labeling cells in the proliferative zone of the growth plates significantly decreased in the line 2 $\mathrm{Tg}$ mice, compared to those in the WT mice. The data were expressed as the percentage of BrdU-positive nuclei versus total proliferative chondrocytes. ${ }^{* *} \mathrm{P}<0.01, \mathrm{n}=5$. Scale bars: $100 \mu \mathrm{m}$. 
useful animal model to study the function of DPP in vivo. Due to the special chemical feature of DPP, it is a challenge to generate specific anti-DPP antibodies. In these transgenic mice, an HA-tag was inserted at the amino-terminus of DPP to allow the detection of the transgenic DPP protein with an anti-HA antibody. IHC analyses with the monoclonal antiHA antibody showed that the DPP protein was found in the ECM of the long bones, suggesting that the DPP protein was properly secreted in vivo. The predicted molecular weight for mouse DPP is about $50 \mathrm{kDa}$. However, the actual size of mouse DPP was not known, due to lack of specific anti-DPP antibody. By taking advantage of HA tag, we detected a smear of HA-DPP protein with an observed size ranging from 90 to $200 \mathrm{kDa}$ in both conditioned medium harvested from HEK-293 EBNA cells transfected with HA-DPP-expressing construct and bone extracts of Collal-HA-DPP transgenic mice. These observations suggest that HA-DPP has undergone extensive posttranslational modifications in both HEK-293 EBNA cells and osteoblasts. Therefore, this specific transgenic model provides a novel tool to study the subcellular and extracellular localization of DPP and to monitor the posttranslational modification of DPP in vivo.

DPP is a highly phosphorylated and acidic molecule. While a number of studies have suggested that it plays an important role in biomineralization through initiating hydroxyapatite crystal nucleation and modulating crystal growth, most of these studies were performed in an in vitro cell-free system..$^{27,28,37-40}$ In this study, we showed that overexpression of DPP in the osteoblast/osteocyte lineage resulted in reduced bone formation and spontaneous bone fractures. As the spontaneous bone fractures were only observed in the line 1 transgenic mice, but not in the line 2 transgenic mice, these bone fractures were most likely associated with the much thinner bones formed in the line 1 transgenic mice. Our current findings suggest that excessive DPP may suppress biomineralization and also indicate that the in vivo biomineralization is a rather complicated process.

In addition, we also showed that the CollalHA-DPP transgenic mice displayed small skeleton and shorter bone length. The shorter bone length was apparently due to the reduced cell proliferation in the proliferating zone of the growth plates, but not due to a defect in the chondrocyte differentiation. Fibroblast growth factor 3 (Fgfr3) plays essential roles in regulating longitudinal bone growth through suppressing both proliferation and differentiation of the growth plate chondrocytes. ${ }^{41}$ Accordingly,
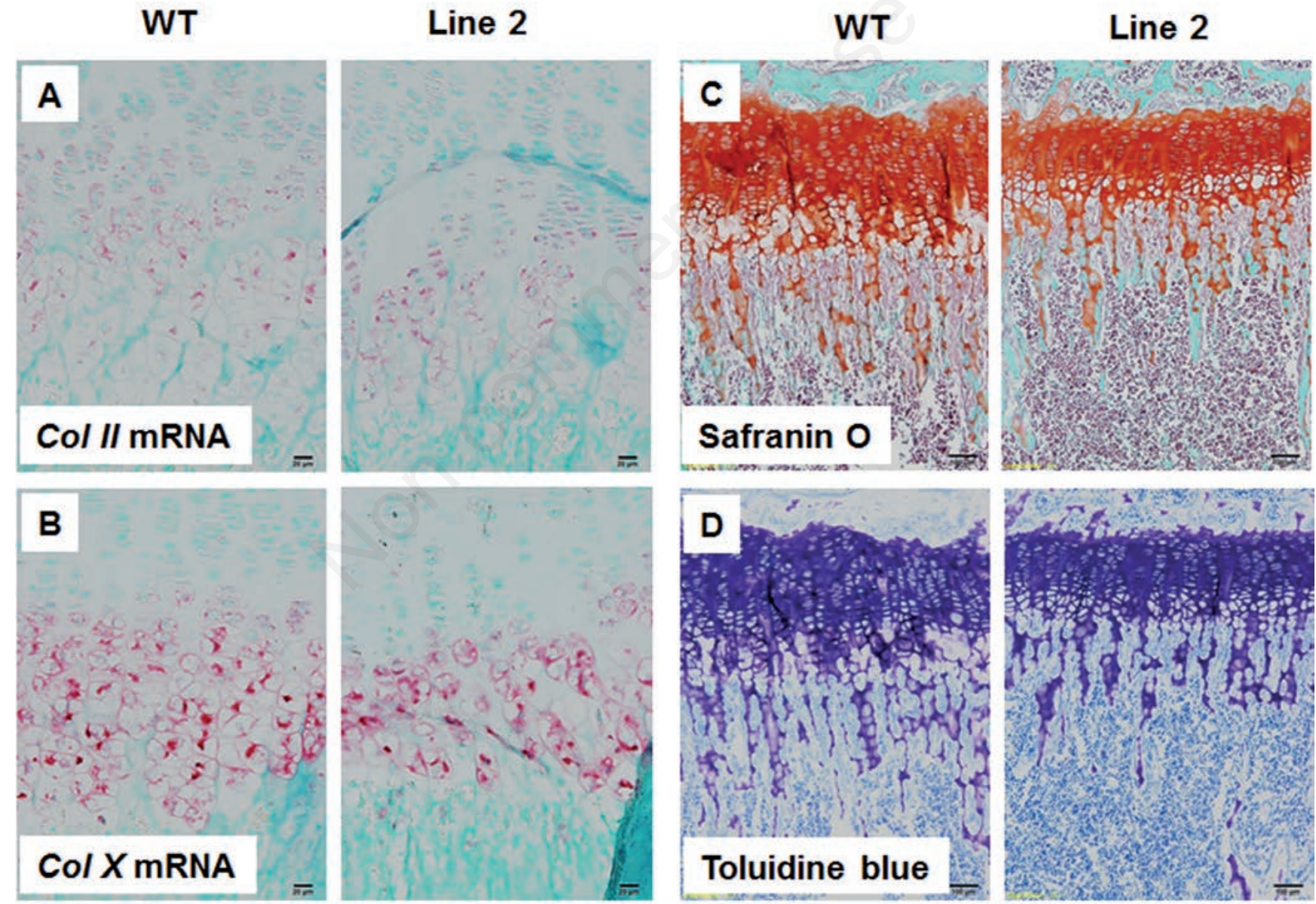

Figure 7. Chondrocyte differentiation in the growth plates of the line 2 transgenic mice. In situ hybridization (ISH) staining of Col II (A) and $\mathrm{Col} \mathrm{X}$ (B) on the sagittal sections of tibia growth plate indicated that there was no apparent difference in signal intensities (pink/red color) for both Col II and Col X mRNAs between the 10-day-old line 2 transgenic mice and the WT mice. Safranin O (C) and Toluidine Blue (D) stainings of the sagittal sections of the tibia growth plates from 3-week-old mice. Both stainings showed a narrower zone of cartilage in the growth plate in the $\mathrm{Tg}$ mice compared to that in the WT mice, but the staining intensity appeared to be similar between the Tg and WT mice. Scale bars: A,B) $20 \mu \mathrm{m}$; C,D) $100 \mu \mathrm{m}$. 
gain of function mutations in FGFR2 gene results in achondroplasia (ACH) or much more severe and lethal form of dwarfism known as thanatophoric dysplasia (TD) in humans. ${ }^{42-45}$ Therefore, we determined the level of Fgfr3 expression in the growth plate chondrocytes by immunohistochemistry. No apparent difference was observed in Fgfr2 expression in the line 2 transgenic mice and wild-type mice (data not shown). This was consistent with our other findings, showing that only proliferation of growth plate chondrocytes were affected, but growth plate chondrocyte differentiation appeared to be normal in the line 2 transgenic mice. These observations suggest that the growth plate defects are unlikely caused by elevated Fgfr3 signaling. How transgenic expression of HA-DPP causes the growth plate defects remains to be further studied. Although the Colla1-HA-DPP transgene was mainly active in the osteoblast/osteocyte lineage, a low level of HA-DPP might also be expressed in the growth plate chondrocytes, but was not readily detected by immunohistochemistry. Such a low level of HA-DPP may account for the growth plate defects observed in the HA-DPP transgenic mice.

In contrast to DPP, overexpression of DSP in the wild type mouse genetic background did not lead to apparent skeletal defects, but it worsened the dentin and periodontal defects of the Dspp null mice. ${ }^{33}{ }^{46}$ While overexpression of the full-length DSPP did not cause any obvious skeletal defects in the wild type mouse genetic background, it rescued the dentin defects of Dspp null mice. ${ }^{25}$ Furthermore, the failure to process DSPP into DSP and DPP blocked the normal function of DSPP, and failed to rescue the dentin defects of $D s p p$ null mice. ${ }^{25}$ Altogether, these findings not only suggest that the proteolytic processing of DSPP into DSP and DPP is essential for the normal function of DSPP, but also imply that both DSP and DPP are required for the normal function of DSPP in the skeletal and dental development.

In conclusion, we generated transgenic mice overexpressing DPP in the osteoblast/osteocyte lineage and showed that overexpression of DPP inhibited skeletal development.

\section{References}

1. MacDougall M, Simmons D, Luan X, Nydegger J, Feng J, Gu TT. Dentin phosphoprotein and dentin sialoprotein are cleavage products expressed from a single transcript coded by a gene on human chromosome 4. Dentin phosphoprotein DNA sequence determination. J Biol Chem
1997;272:835-42.

2. MacDougall M, Simmons D, Luan X, Gu TT, DuPont BR. Assignment of dentin sialophosphoprotein (DSPP) to the critical DGI2 locus on human chromosome 4 band q21.3 by in situ hybridization. Cytogenet Cell Genet 1997;79:121-2.

3. Qin C, Brunn JC, Cadena E, Ridall A, Tsujigiwa $\mathrm{H}$, Nagatsuka $\mathrm{H}$, et al. The expression of dentin sialophosphoprotein gene in bone. J Dent Res 2002;81:392-4.

4. Baba 0, Qin C, Brunn JC, Jones JE, Wygant JN, McIntyre BW, et al. Detection of dentin sialoprotein in rat periodontium. Eur J Oral Sci 2004;112:163-70.

5. Prasad M, Zhu Q, Sun Y, Wang X, Kulkarni A, Boskey A, et al. Expression of dentin sialophosphoprotein in non-mineralized tissues. J Histochem Cytochem 2011;59: 1009-21.

6. Alvares K, Kanwar YS, Veis A. Expression and potential role of dentin phosphophoryn (DPP) in mouse embryonic tissues involved in epithelial-mesenchymal interactions and branching morphogenesis. Dev Dyn 2006;235:2980-90.

7. Xiao S, Yu C, Chou X, Yuan W, Wang Y, Bu $\mathrm{L}$, et al. Dentinogenesis imperfecta 1 with or without progressive hearing loss is associated with distinct mutations in DSPP. Nat Genet 2001;27:201-4.

8. Zhang X, Zhao J, Li C, Gao S, Qiu C, Liu P, et al. DSPP mutation in dentinogenesis imperfecta Shields type II. Nat Genet 2001;27:151-2.

9. Sreenath T, Thyagarajan T, Hall B, Longenecker G, D'Souza R, Hong S, et al. Dentin sialophosphoprotein knockout mouse teeth display widened predentin zone and develop defective dentin mineralization similar to human dentinogenesis imperfecta type III. J Biol Chem 2003;278: 24874-80.

10. von Marschall Z, Mok S, Phillips MD, McKnight DA, Fisher LW. Rough endoplasmic reticulum trafficking errors by different classes of mutant dentin sialophosphoprotein (DSPP) cause dominant negative effects in both dentinogenesis imperfecta and dentin dysplasia by entrapping normal DSPP. J Bone Miner Res 2012;27:1309-21.

11. Verdelis K, Ling Y, Sreenath T, Haruyama N, MacDougall M, van der Meulen MC, et al. DSPP effects on in vivo bone mineralization. Bone 2008;43:983-90.

12. Yamakoshi Y, Hu JC, Iwata T, Kobayashi K, Fukae M, Simmer JP. Dentin sialophosphoprotein is processed by MMP-2 and MMP-20 in vitro and in vivo. $\mathrm{J}$ Biol Chem 2006;281:38235-43.

13. von Marschall Z, Fisher LW. Dentin sialophosphoprotein (DSPP) is cleaved into its two natural dentin matrix products by three isoforms of bone morphogenetic protein-1 (BMP1). Matrix Biol 2010;29: 295-303.

14. Tsuchiya S, Simmer JP, Hu JC, Richardson AS, Yamakoshi F, Yamakoshi Y. Astacin proteases cleave dentin sialophosphoprotein (Dspp) to generate dentin phosphoprotein (Dpp). J Bone Miner Res 2011; 26:220-8.

15. Butler WT, Bhown M, Brunn JC, D’Souza RN, Farach-Carson MC, Happonen RP, et al. Isolation, characterization and immunolocalization of a $53-\mathrm{kDal}$ dentin sialoprotein (DSP). Matrix 1992;12:343-51.

16. Qin C, Brunn JC, Baba 0, Wygant JN, McIntyre BW, Butler WT. Dentin sialoprotein isoforms: detection and characterization of a high molecular weight dentin sialoprotein. Eur J Oral Sci 2003;111:235-42.

17. Yamakoshi Y, Hu JC, Fukae M, Zhang H, Simmer JP. Dentin glycoprotein: the protein in the middle of the dentin sialophosphoprotein chimera. J Biol Chem 2005; 280:17472-9.

18. Veis A, Perry A. The phosphoprotein of the dentin matrix. Biochemistry 1967;6:2409-16.

19. Lee SL, Veis A, Glonek T. Dentin phosphoprotein: an extracellular calcium-binding protein. Biochemistry 1977;16:2971-9.

20. Butler WT, Bhown M, DiMuzio MT, Cothran WC, Linde A. Multiple forms of rat dentin phosphoproteins. Arch Biochem Biophys 1983;225:178-86.

21. Butler WT, Bhown M, Dimuzio MT, Linde A. Nonocollagenous proteins of dentin. Isolation and partial characterization of rat dentin proteins and proteoglycans using a three-step preparative method. Coll Relat Res 1981;1:187-99.

22. Zhu Q, Sun Y, Prasad M, Wang X, Yamoah AK, Li Y, et al. Glycosaminoglycan chain of dentin sialoprotein proteoglycan. J Dent Res 2010;89:808-12.

23. Qin C, Baba 0, Butler WT. Post-translational modifications of sibling proteins and their roles in osteogenesis and dentinogenesis. Crit Rev Oral Biol Med 2004;15:126-36.

24. Sun Y, Lu Y, Chen S, Prasad M, Wang X, Zhu Q, et al. Key proteolytic cleavage site and full-length form of DSPP. J Dent Res 2010;89:498-503.

25. Zhu Q, Gibson MP, Liu Q, Liu Y, Lu Y, Wang $\mathrm{X}$, et al. Proteolytic processing of dentin sialophosphoprotein (DSPP) is essential to dentinogenesis. J Biol Chem 2012;287: 30426-35.

26. Linde A, Lussi A. Mineral induction by polyanionic dentin and bone proteins at physiological ionic conditions. Connect Tissue Res 1989;21:197-202; discussion 3.

27. Boskey AL, Maresca M, Doty S, Sabsay B, Veis A. Concentration-dependent effects of 
dentin phosphophoryn in the regulation of in vitro hydroxyapatite formation and growth. Bone Miner 1990;11:55-65.

28. Saito T, Arsenault AL, Yamauchi M, Kuboki Y, Crenshaw MA. Mineral induction by immobilized phosphoproteins. Bone 1997;21:305-11.

29. Butler WT, Ritchie H. The nature and functional significance of dentin extracellular matrix proteins. Int J Dev Biol 1995;39: 169-79.

30. Prasad M, Butler WT, Qin C. Dentin sialophosphoprotein in biomineralization. Connect Tissue Res 2010;51:404-17.

31. Boskey A, Spevak L, Tan M, Doty SB, Butler WT. Dentin sialoprotein (DSP) has limited effects on in vitro apatite formation and growth. Calcif Tissue Int 2000;67:472-8.

32. Suzuki S, Sreenath T, Haruyama N, Honeycutt C, Terse A, Cho A, et al. Dentin sialoprotein and dentin phosphoprotein have distinct roles in dentin mineralization. Matrix Biol 2009;28:221-9.

33. Gibson MP, Liu Q, Zhu Q, Lu Y, Jani P, Wang X, et al. Role of the NH2 -terminal fragment of dentin sialophosphoprotein in dentinogenesis. Eur J Oral Sci 2013;121: 76-85.

34. Lu Y, Qin C, Xie Y, Bonewald LF, Feng JQ. Studies of the DMP1 57-kDa functional domain both in vivo and in vitro. Cells Tissues Organs 2009;189:175-85.

35. Wang X, Wang S, Li C, Gao T, Liu Y, Rangiani A, et al. Inactivation of a novel FGF23 regulator, FAM20C, leads to hypophosphatemic rickets in mice. PLoS Genetics 2012;8:e1002708.

36. Feng JQ, Huang H, Lu Y, Ye L, Xie Y, Tsutsui TW, et al. The Dentin matrix protein 1 (Dmp1) is specifically expressed in mineralized, but not soft, tissues during development. J Dent Res 2003;82:776-80.

37. Stetler-Stevenson WG, Veis A. Type I collagen shows a specific binding affinity for bovine dentin phosphophoryn. Calcif Tissue Int 1986;38:135-41.

38. Traub W, Jodaikin A, Arad T, Veis A, Sabsay B. Dentin phosphophoryn binding to collagen fibrils. Matrix 1992;12:197-201.

39. Hunter GK, Hauschka PV, Poole AR, Rosenberg LC, Goldberg HA. Nucleation and inhibition of hydroxyapatite formation by mineralized tissue proteins. Biochem $\mathrm{J}$ 1996;317(Pt1):59-64.

40. Zurick KM, Qin C, Bernards MT. Mineralization induction effects of osteopontin, bone sialoprotein, and dentin phosphoprotein on a biomimetic collagen substrate. J Biomed Mater Res A 2013;101:1571-81.
41. Narayana J, Horton WA. FGFR3 biology and skeletal disease. Connect Tissue Res 2015;56:427-33.

42. Bellus GA, Hefferon TW, Ortiz de Luna RI, Hecht JT, Horton WA, Machado M, et al. Achondroplasia is defined by recurrent G380R mutations of FGFR3. Am J Hum Genet 1995;56:368-73.

43. Rousseau F, Bonaventure J, Legeai-Mallet L, Pelet A, Rozet JM, Maroteaux P, et al. Mutations in the gene encoding fibroblast growth factor receptor-3 in achondroplasia. Nature 1994;371:252-4.

44. Shiang R, Thompson LM, Zhu YZ, Church DM, Fielder TJ, Bocian M, et al. Mutations in the transmembrane domain of FGFR3 cause the most common genetic form of dwarfism, achondroplasia. Cell 1994;78: 335-42.

45. Tavormina PL, Shiang R, Thompson LM, Zhu YZ, Wilkin DJ, Lachman RS, et al. Thanatophoric dysplasia (types I and II) caused by distinct mutations in fibroblast growth factor receptor 3. Nat Gene. 1995;9: 321-8.

46. Gibson MP, Jani P, Wang X, Lu Y, Qin C. Overexpressing the NH-terminal fragment of dentin sialophosphoprotein (DSPP) aggravates the periodontal defects in knockout mice. J Oral Biosci 2014;56:143-8. 